\title{
The Coastal and Marine Geology Program of the U.S. Geological Survey
}

\section{Coastal Issues}

Nearly half of all Americans live within an hour's drive of an ocean, the Gulf of Mexico, or the Great Lakes. The U.S. coastal oceans are an economically vital transportation. commercial. and recreational resource. They provide food, energy, and minerals for the entire Nation; on a global scale, they harbor critical habitat for important animal and plant species.

Changes within the coastal and marine environment. whether naturally occurring or human induced. can endanger our quality of life, threaten property, pose risk to fragile environments, and affect livelihoods. Catastrophic events such as hurricanes. offshore earthquakes, submarine landslides, and tsunamis can have serious economic consequences for coastal communities. Wetland loss increases the threat of flooding, decreases water quality, and threatens wildlife. Degraded sea-floor habitats are failing to support fisheries. The coastal oceans have become a repository for sewage, chemicals, and toxic dredged material, whether discharged offshore or brought downstream by rivers.

All 30 coastal States and the island territories have experienced coastal erosion; many have replenished eroded beaches at great cost. The management challenge faced by all coastal communities will be to balance the competing needs of citizens, government, industry, and the environment.

\section{Program Goals}

The goal of the U.S. Geological Survey's Coastal and Marine Geology Program is to describe coastal and marine systems. By using knowledge of the fundamental geologic processes that create, modify, and maintain coastal and marine systems, program researchers can develop models of these systems. The models can then be used by scientists, planners, and managers to predict future change, such as the effects of a hurricane or of waste disposal.
USGS scientists study coastal and marine issues at both local and regional scales. Because the marine environment is made up of complex interrelated systems that cross political boundaries, the USGS, in collaboration with other Federal, State, and local agencies, is able to address and respond to changing national needs and to develop and maintain long-term national data bases. Credible data are made available to State and local agencies as they consider mitigation strategies and develop land management plans.

Although the program's primary focus is on coastal. estuary, and continental shelf regions, studies encompass the Great Lakes, as well as offshore deep-ocean areas within the U.S. Exclusive Economic Zone (EEZ). Objective scientific information is critical to ensuring the wise use and protection of all the Nation's coastal and offshore resources. Several approaches are taken to accomplish the Program's goals:

1. Fundamental studies improve the understanding of coastal and marine geologic processes. Knowledge gained can be applied in other areas of the Nation and throughout the world.

2. Regional studies increase knowledge of coastal and marine geologic systems. Most are conducted within the EEZ or the Great Lakes, but many issues (such as coral reef health, pollutant transport, mineral resources) cross political borders, requiring international collaboration.

3. Catastrophic event studies address the effect that rare or large-magnitude events have on coastal and marine geologic systems. Hurricanes, earthquakes, tsunamis, floods, and pollutant discharges require rapid response, and a longterm commitment to the acquisition of baseline data is needed.

4. Long-term observations define the time scales and the magnitude of change in geologic systems. Analyses of long-term measurements are essential to distinguish human-induced effects from natural changes. The observations often suggest hypotheses about key processes and identify new directions for investigation. Data from long-term observations provide a range of conditions, including catastrophic and (or) rare events, for use in models.

5. Assessments provide a systematic evaluation of the status of geologic systems or processes. These activities may be undertaken regionally before eventually leading to a national effort. The program also provides coastal and marine geologic expertise for national assessments led by other Federal agencies.

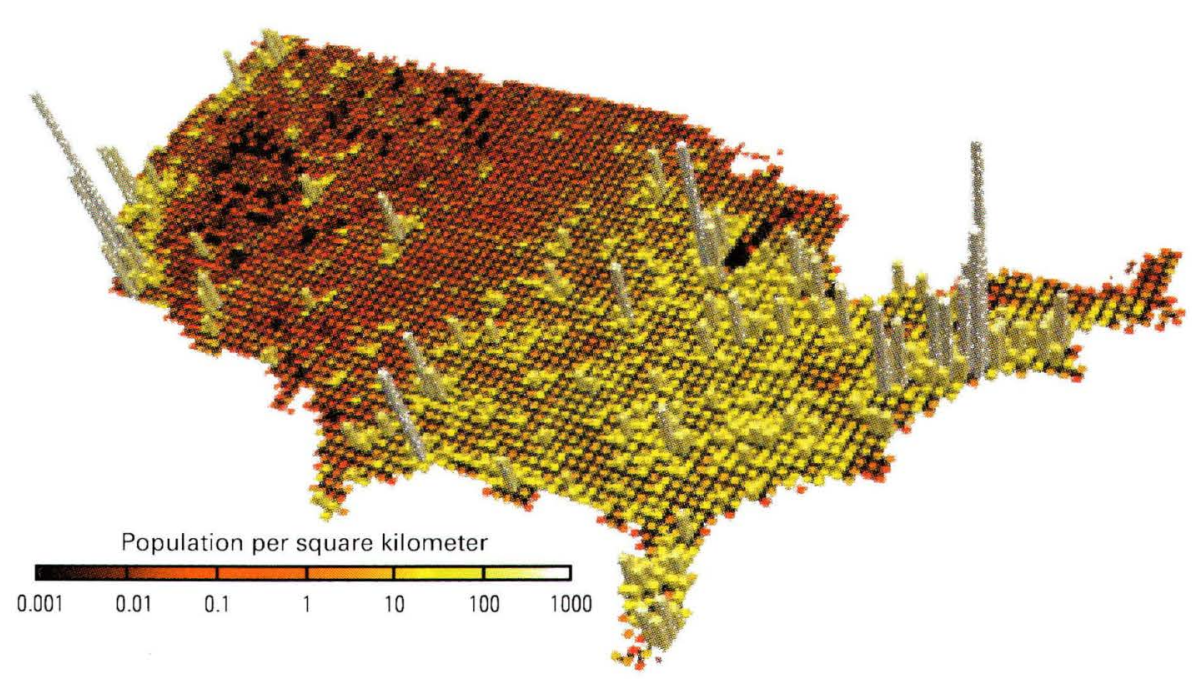

Population in U.S. coastal areas and the Great Lakes region has greatly increased in the past several decades. 


\section{Program Research}

Within the Coastal and Marine Geology Program, four areas of national importance have been identified: Environmental Quality and Preservation, Natural Hazards and Public Safety, Natural Resources, and Information and Technology.

\section{Environmental Quality and Preservation}

Geologic issues influence the long-term quality and preservation of coastal and marine environments. USGS projects are undertaken on issues of pollution and waste disposal, fragile environments, marine reserves and biologic habitats, and geologic records of environmental change. Results from these studies improve our understanding of geologic processes so that natural changes to the coast and sea floor can be predicted. Models of these systems allow the influence of human activities to be measured and evaluated.

\section{Natural Hazards and Public Safety}

Certain hazards, such as offshore earthquakes, tsunamis, and submarine landslides, are catastrophic. Other hazards, coastal and nearshore erosion for example, are the result of longer term processes. Natural hazards studies improve our understanding of the frequency and distribution of catastrophic events and the geologic processes at work in affected coastal regions. The research conducted in this area helps us learn about the origin of natural marine geologic hazards and their influence on people, property, and the environment.

\section{Natural Resources}

Studies of coastal and marine water, energy, and mineral resources provide an understanding of how the resources were formed, where they are located, what their chemical composition is, and how easily they may be extracted. Program investigations currently address water resources in coastal aquifers; strategic minerals such as manganese phosphates and cobalt; and conventional energy resources such as petroleum and natural gas as well as new potential resources such as methane gas. In addition to helping scientists construct more accurate resource models, companion studies will help determine the effect of resource extraction on marine ecosystems.

\section{Information and Technology}

Information and technology research addresses the need for a national source of information about the geology of our marine realms. Accurate scientific information is critical to manage and protect marine environments and resources. Current efforts include systematic mapping of the coast and sea floor; building comprehensive user-friendly information banks; assessing resources and environments; and designing improved instrumentation, technology, and facilities.

\section{Program Operations}

\section{Facilities}

The program's 250 scientists and support staff are primarily located at three regional sites: Menlo Park, California; St. Petersburg, Florida; and Woods Hole, Massachusetts. Facilities are co-located with other Federal and academic institutions in order to facilitate cooperation and to share expertise and resources such as specialized marine equipment.

\section{Funding}

The USGS Coastal and Marine Geology Program's budget in fiscal year 1997 is $\$ 37$ million. In addition to appropriated funds, financial support for cooperative work is received from other agencies, such as the Office of Naval Research, the Minerals Management Service, and the National Oceanographic and Atmospheric Administration. Program funds support research in the academic community and at State agencies.

\section{For more information}

S. Jeffress Williams, Coordinator Coastal and Marine Geology Program U.S. Geological Survey MS 915 National Center Reston, VA 20192

E-mail: jwilliams@usgs.gov URL: http://marine.usgs.gov

Locations where USGS Coastal and Marine Geology Program research is carried out.

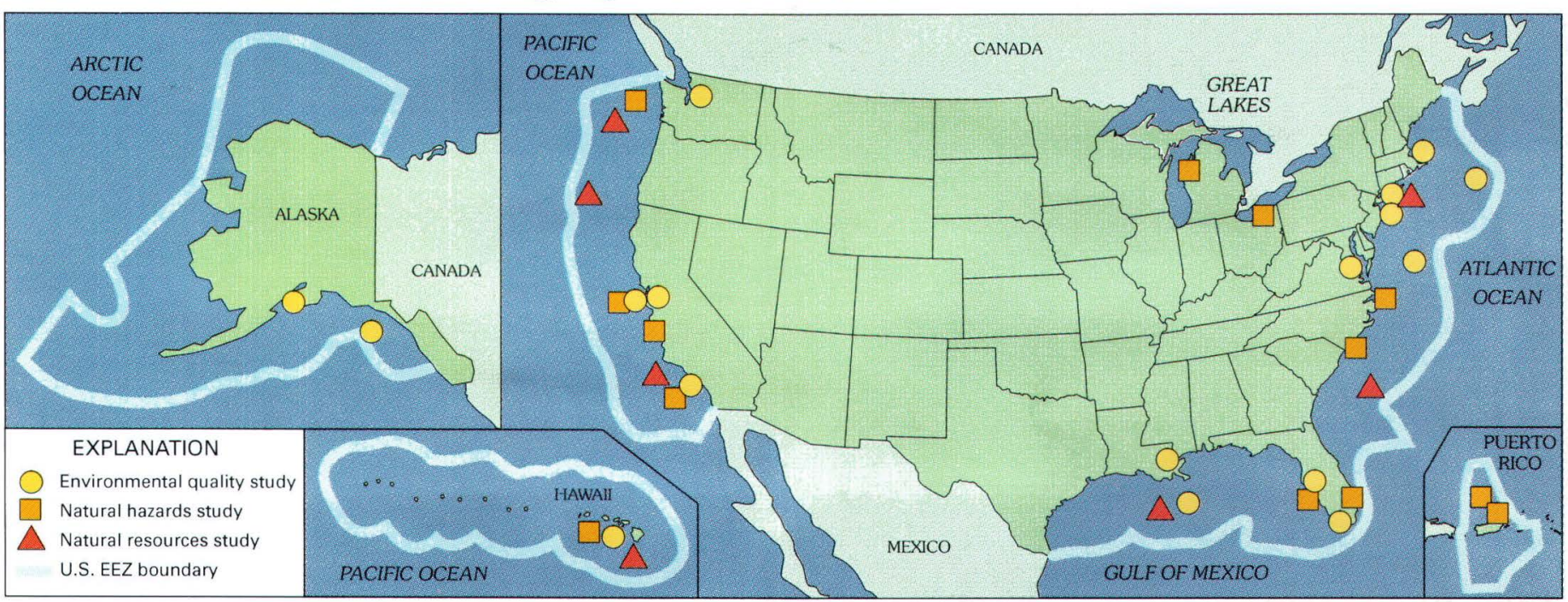

